\title{
A ESSÊNCIA DO RISO - REFLEXÕES SOBRE A TRADUÇÃO DO ROMANCE “GATO MURR”, DE E. T. A. HOFFMANN
}

\author{
Maria Aparecida Barbosa \\ Universidade Federal de Santa Catarina \\ mabarbos@cce.ufsc.br
}

\begin{abstract}
Resumo: O propósito deste artigo é refletir sobre minha tentativa de obter o resultado cômico decorrente do embate intrínseco das diversas feições da natureza humana na versão em português do romance Reflexões do
\end{abstract} Gato Murr, de E. T. A. Hoffmann.

Palavras-chave: tradução literária, crítica de tradução, crítica literária.

\begin{abstract}
The purpose of this article is to reflect on my attempt of getting the comic result that comes from the intrinsic conflicts of human nature within the Portuguese version of E. T. A. Hoffmann Lebensansichten des Katers Murr.
\end{abstract}

Keywords: literary translation, translation criticism, literary criticism.

O riso vem da convicção de superioridade excessiva, afirmou Baudelaire ${ }^{1}$. No fundo, o riso é a expressão de um orgulho inconsciente: "imagine, que paspalho! Eu não sou assim!" Em sua teoria do cômico, ele distingue o grotesco cômico absoluto da respectiva antítese, o cômico significativo, sendo o último de fácil compreensão e acessível ao homem da rua. O acesso ao primeiro, no entanto, requer intuição.

Consoante à opinião de que o escritor E. T. A. Hoffmann soube como ninguém perceber as nuanças e as feições múltiplas da natureza humana, a fim de, com elevado senso de autocrítica, criar a figura do músico e compositor Kreisler e seu duplo e oposto, o 
pretensioso poeta Gato Murr, propus-me ao projeto de traduzir do alemão para o português o romance Reflexões do Gato Murr e uma fragmentada biografia do compositor Johannes Kreisler em folhas dispersas de rascunho - editado por E. T. A. Hoffmann ${ }^{2}$.

O artista Ernst Theodor Wilhelm Hoffmann (Königsberg, 1776 - Berlin, 1822) alterou seu terceiro prenome para Amadeus, demonstrando radicalmente, por meio desse gesto, sua admiração pelo músico Wolfgang Amadeus Mozart (Salzburg, 1756 - Wien, 1796). Vale dizer que Hoffmann também era músico erudito e compositor de óperas, sendo que uma delas, Undine, foi encenada com sucesso no Teatro de Berlin em 1816. Apesar disso, ele não se tornou conhecido nem alcançou grande êxito de público, especialmente na França, a partir de 1830, devido às suas composições musicais; sua projeção deve-se sim à sua obra literária. O escritor deixou 80 contos e 2 romances.

Ao traduzir o romance Gato Murr, no início do século XXI, isto é, quase duzentos anos depois da publicação em alemão, observei que o desafio maior consistia em compor esse dueto de vozes, a delimitação de discursos correspondentes às duas identidades distintas entre si e coerentes em si mesmas. Pensar sobre minha tentativa de obter na versão em português o resultado cômico decorrente do embate intrínseco da natureza humana a que se referiu o ensaísta francês é o propósito do presente artigo.

Três aspectos do texto em alemão se ressaltaram durante minha leitura e o trabalho da versão, e supus que a tríade perfaria a essência do riso dentro do romance: a forma do romance, a delimitação clara do caráter, sobretudo dos dois protagonistas Murr e Kreisler, e a tematização da natureza.

O livro alterna a autobiografia do gato com anotações referentes à biografia de Kreisler, pois, ao escrever, o gato-escritor rasgara sem cerimônia um livro impresso encontrado na casa de seu dono, e empregara as folhas arbitrariamente, ora como base para seu texto, ora como mata-borrão. As folhas foram mantidas no manuscrito e com ele impressas por distração do editor, como se fizessem parte do mesmo. Tal peculiaridade confere um caráter fragmentário ao 
texto, ademais acentuado pelo fato de ter permanecido inconcluso quando da morte de Hoffmann.

Portanto, ao primeiro relancear de olhos, a estrutura e a formatação do romance se evidenciam como questões primordiais a serem solucionadas na tradução. Mas o resultado da mixórdia, dezessete vezes interrompida no meio das frases por meio de reticências e a intercalação de estranhos excertos com o discurso de um narrador se reportando a outro sujeito, pareceram-me de extrema originalidade. Dentro da fictícia história da composição do livro, o editor cria uma estratégia de identificação das partes, a fim de facilitar a leitura. Aponho a seguir uma ilustração dessas passagens de um discurso ao outro:

Como ela era linda! Seu pêlo alvo cintilava à luz prateada da lua, seus olhos verdes feiticeiros e lânguidos irradiavam centelhas incandescentes.

- Você...

(Folha de macul.) ...tivesse sabido disso um pouco antes, querido leitor, teria lhe informado. Queira Deus, no entanto, que eu não seja forçado a omitir informações relevantes novamente ${ }^{3}$.

Assim, não cheguei a hesitar quanto à decisão de manter esse elemento de incompletude, aliás, bastante contemporâneo. Considerando ademais que ambas as biografias possuem alguns traços funcionando como elos que as vinculam, referências comuns como a figura do Mestre Abraham e temáticas, como a menção estilizada da natureza, concluí que a intermitência só traria benefícios, tanto do ponto de vista estético como formal.

Concomitante à preocupação com o critério formal, aprofundeime no estudo da caracterologia ${ }^{4}$. Para conhecer melhor Kreisler, e delineá-lo em português, foi necessário primeiramente recorrer às passagens de outros contextos hoffmannianos nas quais o personagem emerge. Sem dúvida foram importantes para compreendê-lo a leitura e a tradução de grande parte dos ensaios constantes da 
série denominada Kreisleriana, cuja autoria Hoffmann lhe atribuiu. Trata-se neste caso de compilações de crítica de arte a respeito de teatro, literatura e música ${ }^{5}$, publicados em jornais berlinenses entre 1813 e 1814. Entrementes, em tais ensaios, o autor insere íntimos depoimentos que revelam a alma do artista oprimido pelas convenções sociais vigentes em concertos e saraus burgueses, ocasiões em que ele percebe o "quão maravilhosa é a música, e quão pouco o homem penetra seus intrínsecos segredos".

Sua sensibilidade apurada, julgada por alguns contemporâneos como expressão de uma loucura patogênica, é justificada pelo próprio compositor numa confidência a um personagem-cachorrinho dentro da novela "Notícia das mais recentes aventuras do Cachorro Berganza" " :em certo sentido, é tido como louco todo e qualquer sujeito excêntrico, e parece sê-lo ainda mais, quanto mais zeloso se esforce para inflamar a vida exterior enfadonha e sem cor com sua ardente presença" 7 .

Constatando o mérito da música de Kreisler, o "biógrafo" dos fragmentos do romance informa sobre a produção e o acervo dessas obras musicais:

Foi dito, em algum lugar, que mesmo seus melhores amigos nunca haviam conseguido fazê-lo escrever uma de suas composições. Se é que tenha de fato tomado notas algum dia, então logo em seguida deve ter jogado a obra no fogo, por maior que fosse sua satisfação pessoal. Numa época infeliz, sobre a qual este biógrafo até o momento não está bem informado, quando a irremediável ruína o ameaçava, talvez tudo isso tenha acontecido. Mas, agora, na Abadia de Kanzheim, Kreisler, pelo menos evitava destruir as composições que realmente brotavam do seu íntimo ${ }^{8}$.

O compositor Kreisler parece constituir, portanto, a feição do homem abatido pela queda do paraíso, uma ilustração adâmica da dor provocada pelo desterro humano num mundo inóspito e hostil. Segundo minha leitura de tradutora, o riso advém da aporia e da 
ironia encarnadas na inabalável autoconfiança do escritor Murr. Sua autobiografia nos legou uma série de discursos imbuídos de evidente amor-próprio, mesmo em circunstâncias das mais adversas, nas quais a sensata consciência pediria arrego à lucidez. Tais expressões de nenhuma modéstia, ele às vezes compõe em prosa:

\begin{abstract}
Ah! Enquanto escrevo, flameja sobre minha cabeça o radioso astro que com fiel similaridade cintila no interior de meu cérebro, e eu mesmo sou um cometa iluminado, em elevada glória atravesso o universo, profético e ameaçador. Assim como o cometa eclipsa a luz de todas as estrelas, da mesma maneira, você gato, outro animal ou homem, desaparece sob uma sombra obscura, a meu lado, se não os alumio com os raios de minha genialidade. Não obstante a natureza divina que de mim, espírito fulgurante através da cauda se emana, não sou menos obrigado a compartilhar a sina dos mortais! (...) quisera eu unir-me amável aos mais frágeis, e isso me faz cair em tristeza e dor. Pois me dou conta a cada instante de minha extrema solidão; não pertenço ao século em que vivo, porém a outro porvir de superior formação, pois não existe alma capaz de admitir meus méritos. E me propicia, contudo, uma alegria infinda a admiração, mesmo o elogio dos jovens gatos (...) por mais que se esforcem, não atingem o devido tom apologético, somente gritam "Miau, miau!"9
\end{abstract}

Mas sua forma predileta são os versos:

Oh, arte!, filha d'altas esferas

Consolo das duras penas

Que eu sempre faça algum verso

Fácil, sem muito empenho!

E "Murr", digam sempre as belas,

Cordiais, pequenas, melenas.

"Que no coração do poeta, disperso

No gênio, desperte o engenho!" 10 
Nos dias atuais, sobretudo após as discussões surgidas na França por volta de 1968 sobre os conceitos de texto e intertextualidade, no contexto dos colaboradores da revista Tel Quel ${ }^{11}$, a incapacidade autocrítica do escritor tornou-se mais que nunca uma fórmula infalível de provocar o efeito cômico e o riso. Tanto que à velha fórmula recorrem artistas criativos do início de século XXI, mesmo integrantes da grande indústria do cinema atual como Steve Bendelack, em 2007, no filme "As férias de Mr. Bean", como gostaria de citar. Uma caricatura emblemática do caráter similar ao de Murr foi interpretada por Willem Dafoe, por meio da figura chamada Carson Clay, um diretor de cinema. Dentro do filme, ao participar da première do Festival de Cannes, esse personagem rouba a cena do protagonista ao apresentar ao público uma produção cinematográfica extremamente egocêntrica e monótona.

Deixo, entretanto, a sétima arte como mera ilustração atual da estratégia empregada por Hoffmann há tantos anos, e retomo as questões que demandaram cautela, em meu objetivo de expressar o risível na tradução da história de Murr. Além da forma e da precisão do caráter dos personagens, a tematização da natureza que perpassa em vários momentos, ambas as narrativas, se revela como um fio condutor estilizado, nada afinado com a natureza idealizada que preconizou a escola rousseauniana. Vejamos a seguir algumas das passagens recorrentes no romance, com descrição de bucólicas paisagens:

(...) A última claridade do sol poente estendia-se sobre a floresta como um véu dourado. Nenhuma folha se movia. As árvores e os arbustos esperavam em profundo recolhimento que o vento da tarde viesse acariciá-los. A tranqüilidade da natureza só era interrompida pelo murmúrio do regato borbulhante sobre as pedras brancas ${ }^{12}$.

(...) Por todo o lado, a abundância exuberante, rica bênção da natureza, por todo o lado, a azáfama vibrante e eterna 
da vida! A sorridente paisagem vista do cimo da colina, através das janelas da abadia, aumentava a disposição e ao mesmo tempo proporcionava bem-estar ${ }^{13}$;

ou ainda:

(...) O vale se estendia até os sopés das longínquas montanhas. Numerosas manadas pastavam pelas pradarias recortadas por límpidos regatos, felizes andavam por ali camponeses dos vilarejos distribuídos por ricas plantações de cereais; dos graciosos arbustos ecoava o gorjeio jubiloso dos pássaros, o canto melancólico do berrante reverberava das florestas escuras e remotas, e os barcos ricamente carregados deslizavam sobre o rio largo atravessando a paisagem, e era possível ouvir as saudações alegres dos barqueiros ${ }^{14}$.

Em dado momento, o biógrafo informa que o conde: teria expressado em graciosos versos o romântico desejo de gozar uma vida idílica procul negotii $s^{15}$, numa casa pequenina, às margens de um manso regato sussurrante. Como se respondesse ou plagiasse, Murr prossegue com a confissão: senti com aquele poeta as doces e idílicas alegrias numa casa pequenina, às margens de um regato sussurrante $^{16}$ sombreado por espessas e frondosas trepadeiras de bétula e choronas ${ }^{17}$.

Porém, transcendendo as hipérboles do embevecimento idílico, em alguns momentos essa acepção concede espaço ao seu anacoluto através de sub-reptícias inserções como a fala da personagem Hedwiga à amiga Julia:

(...) você sabe como a natureza para mim não passa de uma galeria de pintura, quadros expostos a fim de inspirar as forças do espírito e a habilidade das mãos, mas agora tudo mudou, já não sinto nada, não pressinto nada além do es- 
panto. Preferiria vagar por salões iluminados, entre pessoas interessantes, a estar só com você nessa noite enluarada ${ }^{18}$.

Ou ainda a tentativa do personagem Kreisler de enaltecer e celebrar a "natureza", nos moldes de Jean-Jacques Rousseau (1712 - 1778), como uma companheira sentimental, não logrando, entretanto, senão impregnar sua conversa de ironia grotesca, bem aos moldes românticos alemães, à medida que se reporta justamente à via indireta de observar a natureza, ou seja, à voga de fazê-lo por intermédio das pinturas de paisagens. $\mathrm{O}$ estilo de representação através de pinturas paisagísticas, aliás, passava àquela época por um fecundo florescimento, incentivado, entre outros, pelo escritor Goethe.

De fato, caríssima princesa, o parque é exuberante, e me encanto, sobretudo, porque tantas árvores são cobertas de folhagem verde, isso eu admiro e aprecio bastante em árvores, arbustos, gramíneas. A cada primavera agradeço ao Criador que a natureza volte a ser verde, e não vermelha, o que seria criticável numa paisagem e jamais se encontra nos melhores paisagistas, como, por exemplo, Claude Lorrain ou Berghem, tampouco em Hackert ${ }^{19}$ que somente confere um pouco de cor ao fundo de suas pradarias ${ }^{20}$.

Como se pode depreender das menções de nomes e opiniões, o romance Gato Murr configurou-se como um palco para o embate crítico e irônico que o autor expressava a respeito de questões efervescentes referentes à sua época. Essas intertextualidades culturais podem ser vistas como um aspecto adicional que, de maneira semelhante à forma, ao duplo e contraditório caráter dos protagonistas e à tematização estilizada da natureza, releva também a excelência do riso e do cômico nesse texto de Hoffmann.

Ao estudar a sátira, a caricatura no ensaio "L'essence du rire", Baudelaire elegeu Hoffmann como o mestre do grotesco cômico absoluto, a arte de apresentar a feiúra moral e psíquica 
do ser humano. Do ponto de vista artístico, ele considera o "comique absolu" uma criação verdadeira, una, primitiva, que mais se aproxima da alegria absoluta que do riso das comédias de costumes. Foi aliando os diversos aspectos expostos neste artigo e refletindo sobre a criação do riso profundo e axiomático apontado por Baudelaire que tentei compor em português a biografia do Gato Murr e seu duplo.

\section{Notas}

1. BAUDELAIRE, Charles. "De l'essence du rire et généralement du comique dans les arts plastiques". Disponível em: http://baudelaire.litteratura.com/ ressources/pdf/oeu_27.pdf. Acesso em: 26 mar. 2008.

2. HOFFMANN, E. T. A. Lebensansichten des Katers Murr nebst fragmentarischer Biographie des Kapellmeisters Johannes Kreisler in zufälligen Makulaturblättern - herausgegeben von E. T. A. Hoffmann. In: Insel E. T. A. Hoffmann, 4 volumes. Frankfurt am Main: Insel, 1967, v. 3, p. 127-497.

3. "Wie schön sie war! Silbern glänzte ihr weißer Pelz im Mondschein, in sanftem schmachtendem Feuer funkelten die grünen Äuglein. - Du... (Mak. Bl.) hättest, geliebeter Leser, das freilich schon etwas früher erfahren können, aber der Himmel gebe, da $\beta$ ich nicht mehr querfeldein springen mu $\beta$, als es bis jetzt schon geschehen." (Hoffmann, 1967, v. 3, p. 289).

4. Na ocasião do projeto de mestrado, julgando esse romance muito complexo, preferi iniciar a pesquisa sobre Hoffmann pela tangente, analisando a novela "O Pote de Ouro", e fazendo uma comparação do ritual de plenitude poética do protagonista Estudante Anselmo com vivências similares de personagens de outros contos do mesmo autor. A partir de então, traduzi vários textos de E. T. A. Hoffmann: os melhores contos de Os irmãos Serapião (inclusive "O quebra-nozes"), de 1816, e os dois romances, Os elixires do diabo, de 1814, e Reflexões do Gato 
Murr. Minha tese de doutorado se refere também, entre outros aspectos, ao caráter de Cardillac, personagem da novela "A senhorita de Scudéry".

5. A série de ensaios denominada Kreisleriana contém, inclusive, uma apreciação sobre o emprego dos vocais nas sinfonias do erudito Ludwig van Beethoven (Bonn,1770 - Wien, 1827), denominada "A música instrumental de Beethoven". Esse ensaio polêmico repercutiu consideravelmente no âmbito dos estudos de música.

6. A novela "Nachricht von den neuesten Schicksalen des Hundes Berganza" surgiu como uma continuação fictícia da novela "Colloquio de los perros", que integra as Novelas ejemplares, de Miguel de Cervantes. O diálogo entre um narrador e o famoso personagem canino retrata a vida cultural e traz episódios envolvendo figuras relevantes da sociedade de Bamberg, cidade alemã onde Hoffmann residiu entre 1808 e 1812, trabalhando como professor de música e maestro do teatro.

7. "In gewissem Sinn ist jeder nur irgend exzentrische Kopf wahnsinnig und scheint es desto mehr zu sein, je eifriger er sich bemüht, das äußere matte, tote Leben durch seine inneren glühenden Erscheinungen zu entzünden". (Hoffmann, op. cit., v. 1, p. 83).

8. "Irgendwo hei $\beta t$ es von dem Kapellmeister Johannes Kreisler, da $\beta$ seine Freunde es nicht dahin hätten bringen können, da $\beta$ er eine Komposition aufgeschrieben, und sei dies wirklich einmal geschehen, so habe er doch das Werk, soviel Freude er auch über das Gelingen geäußert, gleich nachher ins Feuer geworfen. So mag es sich begeben haben, in einer sehr verhängnisvollen Zeit, die dem armen Johannes den rettungslosen Untergang drohte, von der gegenwärtiger Biograph bis jetzt aber nicht recht viel wei $\beta "$. (Hoffmann, op. cit., v. 3, p. 368).

9. "Ha! indem ich dieses schreibe, flammt über meinem Haupt das herrliche Gestirn, das in treuer Verwandtschaft in meine Seele hinein-, aus meiner Seele hinausleuchtet $-\mathrm{ja}$, ich fühle den glühenden, sengenden Strahl des langgeschweiften Kometen auf meiner Stirne, - ja, ich bin selbst der glänzende Schwanzstern, das himmlische Meteor, das in hoher Glorie prophetisch dräuend durch dir Welt zieht. So wie der Komet alle Sterne überleuchtet, so verschwindet ihr, stell' ich nur nicht meine Gaben unter den Scheffel, sondern lasse mein Licht gehörig leuchten, und das dependiert ganz von mir - ja, so verschwindet ihr alle in finstre Nacht, ihr Kater, andere Tiere und Menschen! - Aber trotz der göttlichen Natur, die aus mir, dem geschwänzten Lichtgeist, herausstrahlt, teile ich doch nicht das Los aller Sterblichen? - Mein Herz ist zu gut, ich bin ein zu empfindsamer Kater, 
möchte mich gern gemütlich anschließen den Schwächern und gerate darüber in Trauer und Herzeleid. - Denn muß ich nicht überall gewahren, daß ich allein stehe wie in der tiefsten Einöde, da ich nicht dem jetzigen Zeitalter, nein, einem künftigen der höhern Ausbildung angehöre, da es keine einzige Seele gibt, die mich gehörig zu bewundern versteht? Und es macht mir doch so viel Freude, wenn ich tüchtig bewundert werde, selbst das Lob junger gemeiner ungebildeter Kater tut mir unbeschreiblich wohl. (...) sie können doch, bei aller Anstrengung, nicht den rechten Lobposaunenton treffen, schreien sie auch noch so sehr Mau Mau! (Hoffmann, op. cit., v. 3, p. 282).

10. "Ja Kunst! Du Kind aus hohen Sphären,

Du Trösterin im tiefsten Leid, O! - Verslein la $\beta$ mich stets gebären,

Mit genialer Leichtigkeit.

Und: 'Murr', so sprechen edle Frauen,

Hochherz'ge Jünglinge, 'o Murr;

Du Dichterherz, ein zart Vertrauen

Weckt in der Brust dein sü $\beta$ Gemurr!'” (Hoffmann, op cit., p. 432).

11. A revista Tel Quel foi fundada por Phillipe Sollers. Dela participaram Rolland Barthes, Michel Foucault, Jacques Derrida e outros. No artigo "Teoria do conjunto", de 1968, o editor Sollers postula que "o texto pertence a todos, a ninguém, ele não saberia ser um produto acabado".

12. "Wie ein goldner Schleier lag der Schein der sinkenden Sonne ausgebreitet über dem Walde. Kein Blättlein rührte sich. In ahnungsvollem Schweigen harrten Baum und Gebüsch, dass der Abendwind komme und mit ihnen kose. Nur das Getöse des Waldbachs, der über weisse Kiesel fortbrauste, unterbrach die tiefe Stille”. (Hoffmann, op. cit., v. 3, p. 167).

13. “Überall üppige Fülle, reichlich gespendeter Segen der Natur, überall reges, ewig forttreibendes Leben. Die Aussicht in die lachende Landschaft vom Hügel herab, aus den Fenstern der Abtei, erhob das Gemüt und erfüllte es zugleich mit innigem Wohlbehagen”. (Hoffmann, op cit., p. 366).

14. "Dieses Tal breitete sich aus bis an den Fuß des fernen Gebirges. Zahlreiche Herden weideten in den von spiegelhellen Bächen durchschnittenen Wiesengründen, fröhlich zogen die Landleute aus den Dörfern, die hin und wieder verstreut lagen, durch die reichen Kornfelder, jubelnder Gesang der Vögel scholl aus den 
anmutigen Gebüschen, sehnsüchtiger Hörnerschall rief herüber aus der fernen dunklen Waldung, beschwingt mit weißen Segeln, glitten schwer beladene Kähne auf dem breiten Fluß, der das Tal durchströmte, schnell vorüber, und man vernahm die frohen Grüße der Schiffer”. (Hoffmann, op cit., p. 366).

15. Em latim, "feliz daquele que está longe dos negócios", é uma expressão do $2^{\circ}$ Epodo de Horácio.

16. “(...) daß er den romanhaften Wunsch, in einem kleinen Hause, an einem murmelnden Bach, mit einigem Hausvieh ein einsames idyllisches Leben procul negotiis zu führen, in anmutige Verse gebracht (...)". (Hoffmann, op.cit., v. 3, p. 156).

17. "Ich empfand mit jenem Dichter die süssen, idyllischen Freuden im kleinen Häuschen am Ufer eines murmelnden Bachs, umschattet von düster belaubten Hängebirken und Trauerweiden (...)”. (Hoffmann, op cit., p. 176).

18. “(...) du weißt, daß mir sonst die Natur nichts war als eine Bildergalerie, hingestellt, um die Kräfte des Geistes und der Hand zu üben, aber jetzt ist es anders worden, da ich nichts fühle, nichts ahne, als ihr Entsetzen. Ich möchte lieber in erleuchteten Sälen zwischen bunter Gesellschaft wandeln, als einsam mit dir in dieser mondhellen Nacht”. (Hoffmann, op cit., p. 300).

19. Claude Lorrain (Chamagne/França, 1600 - Roma 1682) era um conhecido paisagista. Nicolaes Pietersz Berghem (Holanda, 1620 - 1683) pintava paisagens ao estilo italiano. Philipp Hackert (1737 - 1807) compunha paisagens italianas. Goethe dedicou-lhe um elogio: "Philipp Hackert - esboço biográfico sobretudo a partir de seus próprios ensaios".

20. "In der Tat, sprach der Kapellmeister, in der Tat, gnädigste Prinzessin, der Park ist herrlich, und ganz besonders ist es mir lieb, daß sämtliche Bäume grünes Laub tragen, welches ich überhaupt an allen Bäumen, Sträuchern und Gräsern sehr bewundere und verehre, und jeden Frühling dem Allmächtigen danke, daß es wieder grün worden und nicht rot, welches in jeder Landschaft zu tadeln, und bei den besten Landschaftern, wie z.B. Claude Lorrain oder Berghem, ja selbst bei Hackert, der bloß seine Wiesengründe was weniges pudert, nirgends zu finden" (Hoffmann, op cit., p. 259). 